\begin{tabular}{|c|c|c|c|c|c|c|}
\hline \multirow{4}{*}{ Impact Factor: } & ISRA (India) & 3.117 & SIS (USA) & $=0.912$ & ICV (Poland) & $=6.630$ \\
\hline & ISI (Dubai, UAE & $=0.829$ & РИНЦ (Russia & $=0.156$ & PIF (India) & $=1.940$ \\
\hline & GIF (Australia) & $=0.564$ & ESJI (KZ) & $=5.015$ & IBI (India) & $=4.260$ \\
\hline & JIF & $=1.500$ & SJIF (Morocco & $=5.667$ & & \\
\hline
\end{tabular}

\begin{tabular}{|c|c|}
\hline $\begin{array}{l}\text { SOI: } \underline{1.1 /} \\
\text { International S } \\
\text { Theoretical } \mathbf{\&}\end{array}$ & $\begin{array}{l}\frac{T A S}{\text { DOS }} \text { DOentific Journal } \\
\text { Applied Science }\end{array}$ \\
\hline p-ISSN: 2308-4944 (print) & e-ISSN: 2409-0085 (online) \\
\hline Year: 2018 & Volume: 68 \\
\hline Published: 20.12 .2018 & http://T-Science.org \\
\hline
\end{tabular}

SECTION 25. Technologies of materials for the light and textile industry.
QR - Issue

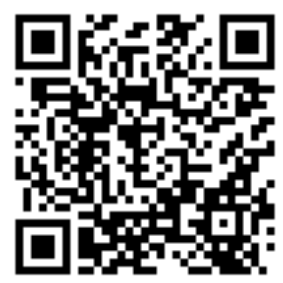

Datalya Bekk
Dovosibirsk State University of Architecture,

Design, Arts

Lyudmila Belova

$\mathrm{Ph}$. D. in engineering scince, Novosibirsk Institute of Technology (a branch) of The Kosygin State University (Technologies. Design. Art)

Tatyana Lapina Senjor Lecturer. Novosibirsk Institute of Technology (a branch) of The Kosygin State University

(Technologies. Design. Art)

\title{
FEATURES CUSTOMIZATION OF ORTHOPEDIC SHOES FOR CHILDREN WITH CEREBRAL PALSY
}

\begin{abstract}
The search of scientific information was carried out in order to expand opportunities for rehabilitation of people having low limbs (legs and feet) diseases. The techniques were developed for customizing of the orthopedic footwear intended for different abnormalities of low limbs. Having studied the abnormalities in movements and having carried out the anthropometric examinations of feet, the classifications of corrective elements of an orthopedic insole, hard details and typical constructions of orthopedic boots were developed, as well as the classification of boots was created taking into account the rehabilitation effect.

Key words: footwear, customizing, designing, orthopedic boots, correction, feet abnormalities

Language: Russian

Citation: Bekk, N. V., Belova, L. A., \& Lapina, T. S. (2018). Features customization of orthopedic shoes for children with cerebral palsy. ISJ Theoretical \& Applied Science, 12 (68), 117-121.

Soi: http://s-o-i.org/1.1/TAS-12-68-21 Doi: crossef https://dx.doi.org/10.15863/TAS.2018.12.68.21

\section{ОСОБЕННОСТИ КАСТОМИЗАЦИИ ОРТОПЕДИЧЕСКОЙ ОБУВИ ДЛЯ ДЕТЕЙ С ДЦП}

Аннотация: Поиск научной информации проводился с иелью расширения возможностей реабилитации людей с заболеваниями нижних конечностей (ног и ступней). Разработаны методики кастомизации ортопедчческой обуви, предназначенной для различных патологий нижних конечностей. Изучив отклонения в движениях, проведя антропометрические исследования стоп детей с ДЦП, изучив ассортимент ортопедической обуви, представленной на рынке, были разработаны классификации корректирующих элементов ортопедической обуви: жестких деталей и типовых конструкций ортопедических ботинок, а также была разработана классификация ботинок с учетом реабилитациионный эффект.
\end{abstract}

Ключевые слова: обувь, кастомизация, проектирование, ортопедическая обувь, коррекция, ортопедия

\section{Introduction}

Дети с заболеванием детский церебральный паралич (ДЦП) составляют значительную долю среди инвалидов. Церебральный паралич является вторым из наиболее распространенных неврологических заболеваний в детстве после задержки психического развития. Разработка средств технической реабилитации и создание безбарьерной среды охватывает многие сферы, включая легкую промышленность. Изучением заболевания ДЦП длительный период времени были заняты специалисты из разных областей. Анализ публикаций, касающихся данной проблемы позволил сформулировать определение 


\begin{tabular}{|c|c|c|c|c|c|c|}
\hline \multirow{4}{*}{ Impact Factor: } & ISRA (India) & $=3.117$ & SIS (USA) & $=0.912$ & ICV (Poland) & $=6.630$ \\
\hline & ISI (Dubai, UAE & $=0.829$ & РИНЦ (Russia) & $=0.156$ & PIF (India) & $=1.940$ \\
\hline & GIF (Australia) & $=0.564$ & ESJI (KZ) & $=\mathbf{5 . 0 1 5}$ & IBI (India) & $=4.260$ \\
\hline & JIF & $=1.500$ & SJIF (Morocco) & $=5.667$ & & \\
\hline
\end{tabular}

ДЦП - это непрогрессирующее поражение головного мозга, возникшее во внутриутробном, родовом или новорожденном периоде, основным клиническим синдромом которого является нарушение двигательных функций, зрения, слуха, речи, интеллекта. Механизм этих нарушений сложен и определяется как временем, так и степенью и локализацией мозгового поражения.

\section{Materials and Methods}

Отличительной чертой нашего времени является выпуск широкого ассортимента ортопедической обуви[1]. Использование ортопедической обуви пациентами с заболеванием ДЦП формирует правильный стереотип ходьбы, подавляет гиперкинезы, устраняет контрактуры, предупреждает развитие деформаций стопы, развивает двигательные навыки.

При производстве новых конструкций ортопедической обуви стоит выделять два направления: изготовление масскастомизированной и у ультракастомизированнной обуви

Масс-кастомизированная ортопедическая обувь - обувь, конструкция которой разработана с учетом средне-типичных особенностей однородной по диагнозу группы пациентов. Кастомизация данной обуви происходит за счет коррекирующих элементов: вкладной ортопедической стельки и конструктивных особенностей моделей, дающих возможность регулировки внутриобувного пространства, для оказания реабилитационного эффекта каркасными деталями обуви. Ультракастомизированной обувью являются модели, разработанные с учетом индивидуальных анатомических особенностей стопы конкретного пациента.

Внутренняя форма обуви обеспечивается колодкой. При производстве масскостомезированной обуви используются стандартные ортопедические колодки. [2, с. 92]. В ультра-кастомизированнной обуви внутриобувное пространство формируется исходя из индивидуальных параметров стопы, путем приправки стандартных ортопедических колодок с учетом особенностей стоп пациента. При более сложных деформациях используют гипсовые слепки стоп. Информационные технологии позволяют получать $3 \mathrm{~d}$ модели стопы и на их основе создавать индивидуальные колодки [3, с. 153].

Помимо впорности ортопедическая обувь должна обеспечивать реабилитационный эффект, который достигается за счет применения жестких каркасных деталей [4, с. 109]. Конструкция ортопедической обуви назначается с учетом всего комплекса деформаций стоп. К специальным каркасным деталям ортопедической обуви для детей с ДЦП относятся жесткий задник, жесткие берцы, жесткий подносок, жесткая союзка, жесткий бочок и т.д. [5, с. 14].

Стоит отметить, что жесткий бочок в большинстве случаев комбинируется с жестким корсетом, жесткими берцами или жестким задником. Проведя анализ частоты использования каркасных деталей в рамках предприятия города Новосибирска («Новосибирский» филиал ФГУП «Московское ПрОП» Минтруда России), было выявлено, что комбинация каркасных деталей в виде сочетания двустороннего жесткого берца с жестким бочком является наиболее распространенной (41\% от общего числа) для профилактики и лечения деформаций нижних конечностей при заболевании ДЦП. Использование жесткого берца без жесткого бочка составляет $22 \%$ [6, с. 190].

Исходя из полученных данных, следует, что при создании масс-кастомизированной обуви, необходимо применять приведенную выше топографию жесткости конструкции. При создании ультра-кастомизированной обуви топография жесткости конструкции определяется врачом ортопедов в индивидуальном порядке.

На фиксацию стопы во внутриобувном пространстве помимо каркасных деталей ортопедической обуви также оказывают влияние наличие ортопедической стельки и способ фиксации обуви на стопе среди которых типовыми являются шнурки, застежки с пряжками, ленты велькро и комбинированные методы фиксации [7, с. 30].

Проанализировав комплекс параметров, принято решение выделить 4 степени фиксации стопы во внутриобувном пространстве, а именно, I - незначительная фиксация, II - увеличенная фиксация, III - значительная фиксация и IV максимальная фиксация. Так, при степень фиксации I достаточно использовать жесткий задник, выполненный из полимерных материалов или кож повышенных толщин. Рекомендуемыми методами фиксации на стопе являются пряжки, ленты велькро или шнурки. Во II степени фиксации в качестве жестких деталей используется высокий жесткий берец. Степень фиксации стопы значительно увеличена. Рекомендуемыми методами крепления на стопе являются пряжки и шнурки. В III - значительной степени фиксации стопы жесткими деталями являются высокий жесткий берец в сочетании с жестким бочком. Данная конструкция обуви предназначена для детей со значительными деформациями в нижних конечностях. Наличие удлиненных жестких деталей в геленочной части, выполненных из полимерных материалов или кож повышенных толщин, значительно 


\begin{tabular}{|c|c|c|c|c|c|c|}
\hline \multirow{4}{*}{ Impact Factor: } & ISRA (India) & $=3.117$ & SIS (USA) & $=0.912$ & ICV (Poland) & $=6.630$ \\
\hline & ISI (Dubai, UAE & $=0.829$ & РИНЦ (Russia) & $=0.156$ & PIF (India) & $=1.940$ \\
\hline & GIF (Australia) & $=0.564$ & ESJI (KZ) & $=\mathbf{5 . 0 1 5}$ & IBI (India) & $=4.260$ \\
\hline & JIF & $=1.500$ & SJIF (Morocco) & $=5.667$ & & \\
\hline
\end{tabular}

увеличивает фиксацию стопы во внутриобувном пространстве в сравнении с предыдущей конструкцией. Рекомендуемыми методами фиксации на стопе являются пряжки и шнурки. Фиксации лентами велькро в данных конструкциях лучше избегать. В IV степени помимо жестких берцев фиксирующих голеностопный сустав, также используются каркасные детали в области союзки и язычка обуви. При этом в обуви достигается максимальная степень фиксации стопы. В конструкции с наличием вышеуказанных жестких деталей рекомендуется использовать шнурки или шнурки в сочетании с лентами велькро.

Таким образом, ортопедическая обувь обеспечивающая I и II степень фиксации и соответствующую жесткость конструкции может изготавливаться как массовый ортопедический товар или мелкими сериями т.е. применимы для создания масс-кастопизированной обуви. III и IV степени фиксации применимы только для создания ультра-кастопизированной обуви, так как направлены на реабилитацию сложных деформаций стоп, характеристики которой индивидуальны для каждого пациента.

Стоит отметить, что в создании положительного реабилитационного эффекта немаловажным является конструкция ортопедической обуви. Так как ассортимент детской ортопедической обуви велик, он требует создания классификации и выявление базовых моделей [8, с. 167]. Для решения данной задачи был произведен анализ конструкций обуви предприятий России, специализирующихся на изготовлении обуви для инвалидов, а именно для детей c заболеванием ДЦП. При анализе ассортимента утепленной обуви, была выявлена наиболее популярная конструкция ботинок с настрочными удлиненными берцами. Высота берцев должна быть достаточной для использования каркасных деталей. В обуви обязательна хорошая раскрываемость, которая достигается за счет удлинения берцев до $\mathrm{V}$ базисной линии или заходя за нее. Методы фиксации данной модели различны, приоритетным являются шнурки, но не исключено использование лент велькро и застежек пряжка. Разнообразие конструкций в данном случае достигалось за счет членения деталей, использования фурнитуры и различных цветовых решений модели [9, с. 158].

При анализе ассортимента летней обуви, выделено 3 базовые модели, имеющую широкую популярность на протезно-ортопедических предприятиях страны.

Это прежде всего сандалии с завышенной берцовой частью и полным открытием для входа стопы. Данная модель наиболее популярна среди моделей летней ортопедической обуви, так как может быть назначена при различных заболеваниях нижних конечностей при ДЦП.

Выделены 3 основные метода фиксации обуви на стопе, а именно: шнурки, ленты велькро, пряжки. Шнурки по всей дуге расхождения для входа стопы создают наибольшую степень фиксации в области голеностопного сустава за счет наименьшего расстояния между фиксирующими элементами (продетыми через блочки шнурками), а так же возможность изменения полнотных параметров обуви за счет стяжки или расслабления шнуровки $[10$, c.130]. Также в производстве обуви имеют место комбинированные методы фиксации на стопе. Наибольшей популярностью пользуется комбинация «лента велькро - пряжка». Это объяснимо удобством самостоятельного надевания и снятия обуви пациентом. В случаях с нарушенной моторикой застежка $\mathrm{c}$ пряжкой становится в большинстве случаев практически невозможной.

Еще одна конструкция с высокими берцами, союзкой с удлиненным язычком, фиксируемым ремнями, также популярна при различных заболеваниях нижних конечностей при ДЦП. Но стоит учитывать, что закрытая пучковая часть обуви создает сложность надевания обуви на пациентов с выраженными контактурами голеностопного сустава и парезами стопы.

За счет союзки с завышенным язычком в обуви достигается усиленная фиксация голеностопного сустава. В конструкции помимо жестких берцев предусмотрено возможное использование жесткого язычка, для увеличения фиксации голеностопного сустава. Предусмотрено 2 вида фиксации на стопе, а именно ленты велькро и пряжки, так же как и в предыдущей модели возможно создание их комбинаций.

Третья выделенная модель - сандалии с завышенными берцами и закрытой носочной частью. Стоит отметить, что данная модель имеет ряд ограничений при наличии значительных деформаций в нижних конечностях. Она категорически не подходит пациентам с выраженными контрактурами голеностопного сустава, парезами стоп, деформациями пальцев и т.д.

В настоящее время разработаны модификации данных моделей. Применяется различное членение деталей, используются нашивные детали, декоративные элементы и фурнитура. При этом конструкция обуви остается исходной и используется как базовая.

Помимо разработки анатомически верной конструкции обуви с высоким реабилитационным эффектом необходимо акцентировать внимание и на массе будущего 


\begin{tabular}{|c|c|c|c|c|c|c|}
\hline \multirow{4}{*}{ Impact Factor: } & ISRA (India) & $=3.117$ & SIS (USA) & $=0.912$ & ICV (Poland) & $=6.630$ \\
\hline & ISI (Dubai, UAE & $=0.829$ & РИНЦ (Russia) & $=0.156$ & PIF (India) & $=1.940$ \\
\hline & GIF (Australia) & $=0.564$ & ESJI (KZ) & $=\mathbf{5 . 0 1 5}$ & IBI (India) & $=4.260$ \\
\hline & JIF & $=1.500$ & SJIF (Morocco) & $=5.667$ & & \\
\hline
\end{tabular}

изделия. Разработки по контролю массы обуви можно разделить на две группы: для сохранения и для изменения центра массы тела.

Положение центра массы тела человека зависит от масс материальных точек, из которого оно состоит [11, с.143-144]. При расчете центра масс необходимо учитывать вес ортопедической обуви, ношение которой является постоянной, т.е. масса обуви так же будет оказывать влияние на изменение положения центра масс. Исходя из методических указаний «Гигиенические требования к детской обуви» и СТО 46429990 010-2015 «Обувь детская с верхом из кожи», масса малодетской обуви не должен превышать 300 гр.; дошкольной - 380гр. Данные касаются повседневной обуви массового производства. В ГОСТ Р 54407-2011 «Обувь ортопедическая. Общие технические условия» указанно, что масса ортопедической обуви с индивидуальными параметрами изготовления не регламентируется. Таким образом, при изготовлении ортопедической обуви рекомендуется придерживаться данных, приведенных в документах, указанных ранее.

Более важным является рассмотрение случаев, при которых масса в полупарах различна. Разница в массе может быть получена из-за разного состава и наличия корригирующих элементов в стельке; разной удельной массы материалов верха обуви, связанной с особенностями конструкций; разной массы фурнитуры, также связанной с особенностями конструкций; разной массы подошв, вызванной наличием корригирующих элементов (компенсация укорочения за счет подошвы, выносы каблуков и т.д.). Для этого, необходим расчет каждой из полупар обуви и ввод дополнительных утяжелителей на полупару с меньшей массой.

\section{Conclusion}

При разработке дизайна изделия, особо стоит отметить, что детали, обеспечивающие балансовое равновесие не должны нарушать биомеханику ходьбы пациента и создавать затруднения при передвижении.

Таким образом, для назначения масскастомизированной или создания ультракастомизированной обуви должна быть рассмотрнна вся вышепредставленная классификация обуви исходя из реабилитационного эффекта.

\section{References:}

1. Kostyleva, V. V. (2016). Razrabotka konstrukcij obuvi po pokazatelyam ortopedicheskogo sta-tusa. (p.160). M.: MGUDT.

2. Arzhannikova, E. E. (2016). Konstruirovanie $i$ tekhnologiya ortopedicheskoj obuvi. prakticheskoe posobie. In: E.E. Arzhannikovoj (Eds.). (p.352). SPb.: FGBU SPb NCEHPR im. G.A. Al'b-rekhta.

3. Zahozhaya, T. S., et al. (2014). Razvitie sistem avtomatizirovannogo proektirovaniya $v$ proizvodstve ortopedicheskoj obuvi. (pp.152154). Innovacii -2014.

4. Zahozhaya, T. S., Bekk, N. V., Shelomenceva, O. N., \& Mahotkina, L. Y. (2014). Obespechenie razlichnyh stepenej zhe-stkosti ortopedicheskoj obuvi pri DCP za schet ispol'zovaniya polimernyh karkasnyh detalej. Vestnik KGTU, Kazan', № 13, 108-111.

5. Maksimova, I. A., et al. (2009). Razrabotka i obosnovanie tekhnologii izgotovleniya special'noj obuvi $\mathrm{v}$ usloviyah massovogo proizvodstva. (p.156). M.: Moskovskij gosudarstvennyj universitet dizajna i tekhnologii.

6. Sokolovskij, A. R., Zahozhaya, T. S., \& Bekk, N. V. (2016). Kachestvo $i$ ehstetika profilakticheskoj $i$ ortopedicheskoj obuvi. Sovremennaya pedagogika i obrazovanie: problemy, vozmozhnosti i per-spektivy razvitiya: prakt. Konferencii. (pp.187-191). Taraz (Kazahstan): Izd-vo TIGU.

7. Bekk, N. V., et al. (2016). Modelirovanie, konstruirovanie $i$ kontrol' kachestva ortopedicheskoj obu-vi dlya detej $i$ vzroslyh. Uchebnoe posobie. (p.96). M.: Infra-M..

8. Bekk, N. V., Belova, L. A., \& Lapina, T. S. (2018). Opredelenie bazovyh konstrukuij dlya pacientov $s$ zabolevaniem DCP. Tekhnologii, dizajn, nauka, obrazovanie $\mathrm{v}$ kontekste inklyuzii: sbornik nauch. Trudov, chast' 1 . (p.165-168). M.: RGU im. L.N. Kosygina.

9. Bekk, N. V., Belova, L. A., \& Lapina, T. S. (2018). Osoobennosti inklyuzivnogo dizajna pri sozdanii obuvi dlya detej s zabolevaniem DCP. Innovacii i sovremennye tekhnologii $v$ industrii 


\begin{tabular}{|c|c|c|c|c|c|c|}
\hline \multirow{4}{*}{ Impact Factor: } & ISRA (India) & $=3.117$ & SIS (USA) & $=0.912$ & ICV (Poland) & $=6.630$ \\
\hline & ISI (Dubai, UAE & $=0.829$ & РИНЦ (Russia) & $=0.156$ & PIF (India) & $=1.940$ \\
\hline & GIF (Australia) & $=0.564$ & ESJI (KZ) & $=\mathbf{5 . 0 1 5}$ & IBI (India) & $=4.260$ \\
\hline & JIF & $=1.500$ & SJIF (Morocco) & $=5.667$ & & \\
\hline
\end{tabular}

mody. materia-ly nacional'noj nauchnoprakticheskoj konferencii (15 maya 2018 g.)/ Novosibirskij tekhnologicheskij institut (filial) RGU im. A.N. Kosygina. (p.158). Saratov: Izdvo «Akademiya upravleniya».

10. Bekk, N. V., \& Zahozhaya, T. S. (2014). Konstruktivnye resheniya dlya obespe-cheniya kachestvennoj fiksacii obuvi dlya detej $s$ zabolevaniem DCP. Dizajn, tekhnologii i innovacii v tekstil'noj i legkoj promyshlennosti
(Innovacii - 2014) sbornik materialov Mezhdunarodnoj nauchno-tekhnicheskoj konferencii. (pp.129-131).

11. Romashkina, Y. V., Sineva, O. V., Han, S. R., \& Kostyleva, V. V. (2016). Ocenka raspredeleniya nagruzki na otdely stopy pri hod'be. Aktual'nye problemy inklyuzii: kachestvo zhizni, bezbar'ernaya sreda, obrazovanie bez granic. Sbornik nauchnyh publikacij. (pp. 142-145). 